\title{
Multiplex PCR for detection of MCR genes in clinical fecal samples
}

\author{
Qiumei Xiang ${ }^{1}$, Shuanglan $\mathrm{Hu}^{3}$, Yuebin $\mathrm{Ke}^{2}$, and Shuangfang $\mathrm{Hu}^{2,4, *}$ \\ ${ }^{1}$ School of Public Health, Fujian Medical University, Fuzhou 350801, China \\ ${ }^{2}$ Key Laboratory of Molecular Epidemiology of Shenzhen, Shenzhen Center for Disease Control and Prevention, Shenzhen518055, \\ China \\ ${ }^{3}$ Institute of Bioengineering, Chuangdong Academy of Science, Guangzhou510316, China \\ ${ }^{4}$ Beijing Advanced Innovation Center for Food Nutrition and Human Health, College of Veterinary Medicine, China Agricultural \\ University, Beijing 10083, China
}

\begin{abstract}
Plasmid-mediated colistin-resistance genes have been reported worldwide in recent years. A multiplex polymerase chain reaction (Multi-PCR) protocol was developed to detect transferable colistinresistance genes ( $m c r-1$ to $m c r-6$ ) in Enterobacteria for clinical laboratory purposes. The authors first designed six new primer pairs to amplify $m c r-1$ to $m c r-6$ gene products to achieve stepwise separation of amplicons between 87 to $216 \mathrm{bp}$, then divided these primers into two subgroups with the assistance of a pair of universal primers for the detection of currently described $\mathrm{mcr}$ genes and their variants in Enterobacteria. The protocol was validated by testing 29 clinical isolates of Escherichia coli of human origin, each well characterised and prospectively validated. The Multi-PCR assay showed full concordance with whole-genome sequence data and displayed higher sensitivity and $100 \%$ specificity. The assay could detect all variants of the various $m c r$ alleles described. It was able to detect $m c r-3$ and $m c r-4$ as singletons or in combination. This type of test is critical for the epidemiological surveillance of plasmid-encoded resistance in limited resources conditions, and this method allows rapid identification of $m c r$-positive bacteria and overcomes the challenges of phenotypic detection of colistin resistance.
\end{abstract}

\section{Introduction}

Colistin (polymyxin E) has been used in veterinary medicine worldwide, but human use is restricted in terms of its nephrotoxicity and neurotoxicity [1-3]. The increasing emergence of multidrug-resistant gramnegative bacteria in the past decade has led colistin administration be in a dilemma as colistin sometimes act as the last-resort antibiotic for human infections [1]. Since the first report of mcr-1 [2], mobile colistinresistance (MCR) genes have been found in many clinical and environmental samples. Hitherto, ten types of MCR genes have been reported worldwide [4-14], and MCR genes ranging from $m c r-1$ to $m c r-6$ are frequently found in enterobacteria [15]. Thus the regular surveillance of these human isolated MCR genes also help the appropriate use of colistin in human and animals.

The transferability, high carrying rate and wide distribution of the mcr-1 gene have aroused great concern and anxiety in society. The ongoing introduction of new MCR genes and its variants also is a disadvantage for correct global surveillance. Since the positive growth on selective enrichment media was not equivalent to the presence of $\mathrm{mcr}$ genes, neither phenotypic resistance nor growth on colistin selective media are perfect indicators for the presence of $\mathrm{mcr}$ genes [16], molecular detection methods that targets specific genes are needed. The current routine molecular procedures for MCR gene detection and confirmation depend largely upon technologies such as singleplex polymerase chain reaction (PCR) [17], multilocus sequence typing (MLST) [18] or whole-genome sequencing (WGS) [19] or sequencing approach. Considering the global concerns, we sought to develop and validate a rapid, efficient and inexpensive method that enables screening of relevant isolates and identification of those clinical samples that may harbour plasmid-mediated colistin-resistance genes.

The discovery of MCR genes has raised international concern because the spread of those genes might hamper the efficacy of colistin in clinical use. Therefore the carriage of mcr-lin health individuals was much more associated with the living next to a farm, the production of sheep and freshwater aquaculture, annual consumption of total meat, pork and mutton, and daily intake of aquaculture products[20,21]. It is urgent to develop a reliable molecular which can rapidly detect variable MCR genes popular in China. Here, we describe a multiplex PCR protocol for rapid and reliable detection of $m c r-1, m c r-2, m c r-3, m c r-4, m c r-5$ and $m c r-6$ genes which are frequently found in China for surveillance and epidemiological research, particularly in clinical faecal samples.

\footnotetext{
*Corresponding author: hushuangfang@126.com
} 


\section{Materials and methods}

\subsection{Bacterial strain and growth condition}

Table 1. Bacterial strains used in this study

\begin{tabular}{|c|c|c|c|}
\hline Bacterial strain & $\begin{array}{l}\text { Strains } \\
\text { ID/Source }\end{array}$ & $\begin{array}{c}\mathrm{qPC} \\
\mathrm{R}\end{array}$ & $\begin{array}{l}\text { Shen, et } \\
\text { al.(2018) }\end{array}$ \\
\hline \multicolumn{4}{|l|}{$\begin{array}{l}\text { MCR-positive } \\
\text { strain(n=14) }\end{array}$} \\
\hline \multicolumn{4}{|l|}{$\operatorname{Klebsiella}(\mathrm{n}=3)$} \\
\hline $\begin{array}{l}\text { Klebsiella } \\
\text { pneumoniassp. } \\
\text { rhinoscleromatis }\end{array}$ & isolation $1^{\mathrm{a}}$ & + & + \\
\hline $\begin{array}{l}\text { Klebsiella } \\
\text { pneumoniassp. } \\
\text { rhinoscleromatis }\end{array}$ & isolation 2 & + & + \\
\hline $\begin{array}{l}\text { Klebsiella } \\
\text { pneumoniassp. } \\
\text { rhinoscleromatis }\end{array}$ & isolation 3 & + & + \\
\hline \multicolumn{4}{|l|}{$\begin{array}{l}\begin{array}{l}\text { Escherichia } \\
\text { coli }(\mathrm{n}=11)\end{array} \\
\end{array}$} \\
\hline Escherichia coli & isolation 1 & + & + \\
\hline Escherichia coli & isolation 2 & + & + \\
\hline Escherichia coli & isolation 3 & + & + \\
\hline Escherichia coli & isolation 4 & + & + \\
\hline Escherichia coli & isolation 5 & + & + \\
\hline Escherichia coli & isolation 6 & + & + \\
\hline Escherichia coli & isolation 7 & + & + \\
\hline Escherichia coli & isolation 8 & + & + \\
\hline Escherichia coli & isolation 9 & + & + \\
\hline Escherichia coli & isolation 10 & + & + \\
\hline Escherichia coli & isolation 11 & + & + \\
\hline \multicolumn{4}{|l|}{$\begin{array}{l}\text { None MCR-positive } \\
\text { strain }(n=19)\end{array}$} \\
\hline \multicolumn{4}{|l|}{ Enterbacter $(n=4)$} \\
\hline Enterbacter cloacae & CICC $21539^{b}$ & $--^{\mathrm{c}}$ & - \\
\hline Enterbacter sakazakii & ATCC 29544 & - & - \\
\hline $\begin{array}{l}\text { Enterbacter } \\
\text { aerogenes }\end{array}$ & CICC 10293 & - & - \\
\hline $\begin{array}{l}\text { Enterobacter } \\
\text { aerogenes }\end{array}$ & ATCC13408 & - & - \\
\hline \multicolumn{4}{|l|}{$\begin{array}{l}\text { Escherichia } \\
\operatorname{coli}(n=12)\end{array}$} \\
\hline E. coli $\mathrm{O} 157: \mathrm{H} 7$ & CICC 21530 & - & - \\
\hline E. coli $\mathrm{O} 157: \mathrm{H} 7$ & SZCIQ 13813 & - & - \\
\hline E. coli $\mathrm{O} 157: \mathrm{H} 7$ & ADCPC 931 & - & - \\
\hline Escherichia coli & ATCC 9637 & - & - \\
\hline Escherichia coli & SZCIQ eco3 & - & - \\
\hline Escherichia coli & SZCIQ eco5 & - & - \\
\hline Escherichia coli & SZCIQ jm109 & - & - \\
\hline Escherichia coli & CMCC 44104 & - & - \\
\hline Escherichia coli & CMCC 44105 & - & - \\
\hline Escherichia coli & CMCC 44106 & - & - \\
\hline Escherichia coli & CMCC 44111 & - & - \\
\hline Escherichia coli & CGMCC 1.129 & - & - \\
\hline \multicolumn{4}{|l|}{$\operatorname{Klebsiella}(n=2)$} \\
\hline Klebsiella pneumonia & CMCC 46102 & - & - \\
\hline Klebsiella pneumonia & CICC 10781 & - & - \\
\hline Salmonella $(\mathrm{n}=1)$ & & - & - \\
\hline Salmonella dublin & GZCDCdblla & - & - \\
\hline
\end{tabular}

a: ATCC, American Type Culture Collection, Maryland, USA; CMCC, National Center for Medical Culture Collections, Beijing, China; CGMCC, China General Microbiological Culture Collection Center, Beijing, China; CICC, China Center of Industrial Culture Collection; SZCIQ, Shenzhen Entry-Exit Inspection and quarantine bureau; $\mathrm{ADCPC}$, Animal Disease Control and Prevention Center, Guangzhou Center for Disease Control and Prevention. The mean $\mathrm{T} \mathrm{m}$ values are means of three replicate experiments;

b: Clinical faecal sample isolation;

c: Negative signal.

Table 1 lists the 33 bacterial strains used in this study. In addition to MCR-positive Enterobacteriaceae (MCRPE), most MCR gene host bacteria are associated with E. coli, Salmonella, K. pneumoniae and Moraxella [22-25]. Strains with strain identification were purchased from culture collections. Isolates of MCRPE from faecal samples were obtained as described by Shen et al. [17]. All strains listed in Table 1 can be isolated from faecal samples and were genetically identified and characterised by $16 \mathrm{~S}$ RNA sequencing, multilocus sequence typing (MLST) or conventional methods. The strains were grown on appropriate media before DNA extraction. Specifically, Salmonella spp., E. coli and Shigella spp. were aerobically incubated at $37^{\circ} \mathrm{C}$ for 24 $\mathrm{h}$ in Luria-Bertani (LB) broth (Guangdong Huankai Microbial Sci \& Tech Co, Ltd, Guangzhou, China), and K. pneumoniae was aerobically incubated at $37^{\circ} \mathrm{C}$ for 24 $\mathrm{h}$ in nutrient broth (Guangdong Huankai Microbial Sci. $\&$ Tech. Co., Ltd.).

\subsection{Primer design and DNA extraction}

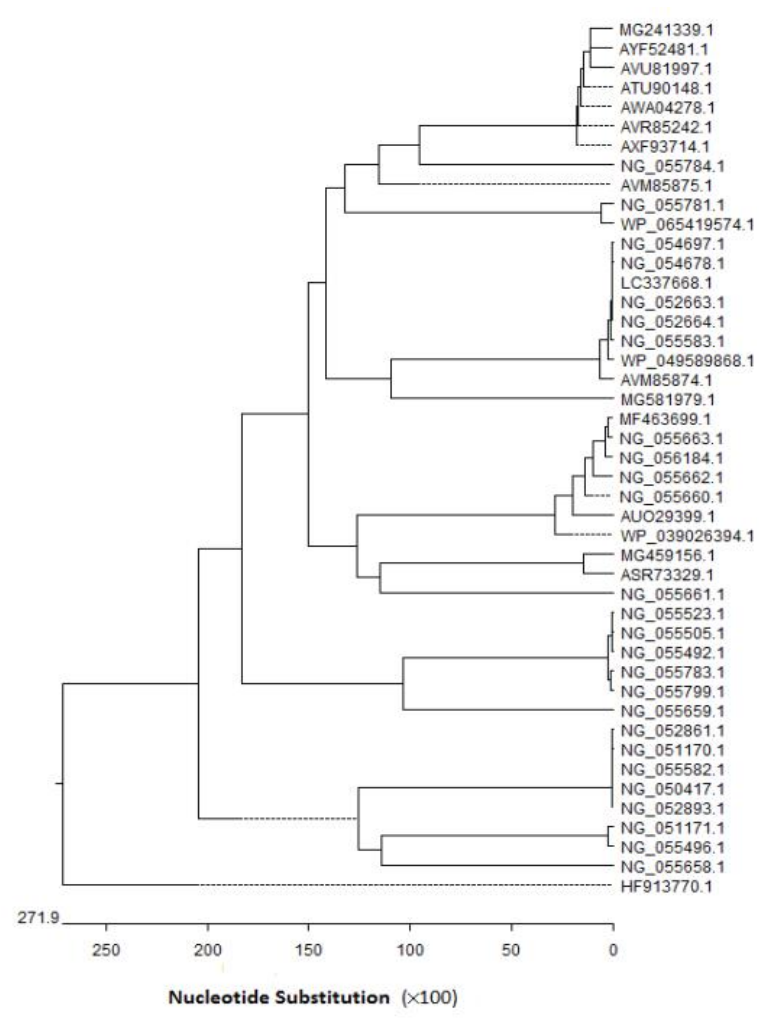

Fig. 1. The nucleotide sequences of the $m c r$ alleles obtained from the GenBank.

The nucleotide sequences of the $m c r$ alleles were obtained from the GenBank database (http://www.ncbi. nlm.nih.gov/) and a comparison was made. Figure 1 lists the accession numbers of these obtained from the 
database. The primers were based on the presumptively conserved sequences of these six genes and their variants using Primer Express 3.0 [26]. To minimise the putative interactions among primers, primer combinations were evaluated for the formation of primer-dimer structures. BLAST analysis was then used to assess the primers' specificity (http://www.ncbi.nlm.nih.gov/). Cell pellets from 1-mL bacterial cultures were used to isolate bacterial DNA using the QIAamp DNA mini kit (Qiagen, USA) or the Tiangen Bacteria DNA Kit (Tiangen Biotech Beijing Co., Ltd., Beijing, China) according to the manufacturer's instructions. The concentration and purity of the extracted DNA samples were spectrophotometrically determined.

\subsection{Real-time PCR analysis}

Resolution melting real-time PCR amplification of small regions of the MCRgenes was performed with a total volume of $20 \mu \mathrm{L}$, which contained $2 \mu \mathrm{L}$ DNA template of each bacteria $(0.5 \mu \mathrm{mol} / \mathrm{L}), 10 \mu \mathrm{L}$ of Premix Taq (Ex Taq Version 2.0) (Takara Bio Group, Dalian, Japan), 2 $\mu \mathrm{L}(10 \mu \mathrm{mol} / \mathrm{L})$ of primers, $1.25 \mu \mathrm{L}$ of Eva-Green (Takara) and $0.2 \mu \mathrm{L}$ of bovine serum albumin (20 $\mathrm{mg} / \mathrm{mL}$ ); nuclease-free water was then added to bring the total reaction volume to $20 \mu \mathrm{L}$. Nuclease-free water was used as the no-template control. the optimised experimental protocol for the ABI 7500 sequencer (Life Technologies, Inc., USA) was as follows: $95{ }^{\circ} \mathrm{C}$ for 10 min, 40 cycles at $95{ }^{\circ} \mathrm{C}$ for $10 \mathrm{~s}$ and $60{ }^{\circ} \mathrm{C}$ for $50 \mathrm{~s}$. A melting curve temperature profile was finally undertaken from $60{ }^{\circ} \mathrm{C}$ to $95{ }^{\circ} \mathrm{C}$ at a melting rate of $0.2{ }^{\circ} \mathrm{C} / \mathrm{s}$. EvaGreen was used as the intercalating dye, and the data were analysed with the manufacturer's software (ABI 7500 software 2.3). For Multiplex PCR, the universal bacteria primers were added at the concentration of 0.4 $\mu \mathrm{mol} / \mathrm{L}$, and other primers were added equally to achieve a system containing primers at concentration of 1 $\mu \mathrm{mol} / \mathrm{L}$.

\subsection{Analytical specificity of real-time PCR assay}

Thirty-three DNA templates were included in this assay, including 14 target bacteria and 19 non-target bacteria (as shown in table 1). The analytical specificity was expressed as the percentage of samples with known identity of the target genes that returned a positive outcome in the assay, whilst the diagnostic specificity was expressed as the percentage of non-target samples with known identity that returned a negative outcome in the assay. All available samples were used to determine the analytical and diagnostic specificity of identification of MCR-positive types.

\subsection{Analytical sensitivity of high-resolution melting real-time PCR assay}

To evaluate the analytical sensitivity of the multiplex PCR method, each strain of $m c r$-positive bacteria was cultured for $16 \mathrm{~h}$ at $37{ }^{\circ} \mathrm{C}$ in tryptic soy broth and used for DNA extraction as described above. DNA from each strain was purified from liquid culture using the
Genomic DNA Purification System (Promega, Madison, WI, USA). The DNA concentrations were spectrophotometrically determined as described above. A series of 10 -fold dilutions for each purified MCR DNA was used for real-time PCR. All samples were processed in triplicate.

\subsection{Detection of mcr variants in faecal samples}

One hundred twelve fresh faecal samples were collected from healthy people with the MGI Easy collection suite for intestinal microbial genetic testing; these samples were suspended in buffer solution (version 3.0, for research only; MGI) and stored at $4{ }^{\circ} \mathrm{C}$ for less than 1 week. After no less than 10 hours of enrichment in colistin-chromagar media, each sample was submitted to the detection methods described by Shen et al. [17] and to our newly developed multiplex PCR.

\subsection{Statistical analysis}

All statistical data analyses were performed using Microsoft Excel. Means and standard deviations of the Tm values were calculated.

\section{Results}

\subsection{Primer design and real-time PCR analysis}

Using the DNA from the six bacteria strains positive for $m c r$ variants (Table 1) as the template, we amplified products ranging from 87 to $216 \mathrm{bp}$ with the specific primer pairs. The differences between the amplified fragments, which were amplified by different primers, resulted in various melting temperature $(\mathrm{Tm})$ values in the six $m c r$ variants. We firstly designed six pairs of primers targeting on six $m c r$ gene types (for example primers for $m c r-3 / m c r-4$ shown in table 2), and then artificially synthesized new primers by adding individual nucleotides as the universal bacteria primers (as shown in table 2) to the $5^{\prime}$ end of the chain while do not change the targeting sites (for example primers for $\mathrm{mcr}-1 / \mathrm{mcr}$ $2 / m c r-5 / m c r-6$ shown in table 2 ). Then we separately test the efficiency of each primer pairs via PCR procedure described in section 2.3.Specifically, for the primers without bacterial universal primers, the Tm peak of $\mathrm{mcr}$ 1 was found at $84.8 \pm 0.01{ }^{\circ} \mathrm{C}$, the Tm peak of $m c r-2$ was detected at $85.2 \pm 0.01{ }^{\circ} \mathrm{C}$, the Tm peak of $m c r-5$ was observed at $84.1 \pm 0.01{ }^{\circ} \mathrm{C}$, the Tm peak of $m c r-6$ was found at $83.3 \pm 0.02{ }^{\circ} \mathrm{C}$, the $\mathrm{Tm}$ peak of $m c r-3$ was detected at $80.7 \pm 0.01{ }^{\circ} \mathrm{C}$, and the Tm peak of $m c r-4$ was observed at $74.8 \pm 0.06{ }^{\circ} \mathrm{C}$. For the primers adding by bacterial universal primers, the Tm peak of $\mathrm{mcr}-1$ was found at $84.8 \pm 0.02{ }^{\circ} \mathrm{C}$, the $\mathrm{Tm}$ peak of $m c r-2$ was detected at $85.2 \pm 0.01{ }^{\circ} \mathrm{C}$, the Tm peak of $m c r-5$ was observed at $84.1 \pm 0.02{ }^{\circ} \mathrm{C}$, the Tm peak of $m c r-6$ was found at $83.3 \pm 0.02{ }^{\circ} \mathrm{C}$, the $\mathrm{Tm}$ peak of $m c r-3$ was detected at $80.7 \pm 0.01{ }^{\circ} \mathrm{C}$ and the Tm peak of $m c r-4$ was observed at $74.8 \pm 0.06{ }^{\circ} \mathrm{C}$. 
Table 2.Primers and amplification fragment.

\begin{tabular}{|c|c|c|}
\hline $\begin{array}{l}\text { Primers } \\
\text { match }\end{array}$ & Primers sequence & $\begin{array}{l}\text { Fragment } \\
\text { length (bp) }\end{array}$ \\
\hline \multicolumn{3}{|l|}{ Group-A } \\
\hline \multirow{2}{*}{$\begin{array}{l}\text { Universal } \\
\text { primer }\end{array}$} & $\begin{array}{l}\text { F: 5' TAGCACACGCAGAGTA } \\
\text { CGTAGCT -3' }\end{array}$ & \\
\hline & $\begin{array}{l}\text { R: 5' CGAGACAGCAGTCAAT } \\
\text { ACCGTC-3' }\end{array}$ & \\
\hline \multirow{2}{*}{$m c r-1$} & $\begin{array}{l}\text { F:5'TAGCACACGCAGAGTAC } \\
\text { GTAGCTCTCGTTGGCTTAGA } \\
\text { TGACT-3' }\end{array}$ & $\begin{array}{l}m c r- \\
1: 216 \mathrm{bp}\end{array}$ \\
\hline & $\begin{array}{l}\text { R: 5' CGAGACAGCAGTCAAT } \\
\text { ACCGTCGGACTGATGTTCGC } \\
\text { ACTT-3' }\end{array}$ & \\
\hline \multirow[t]{2}{*}{$m c r-2$} & $\begin{array}{l}\text { F:5'TAGCACACGCAGAGTAC } \\
\text { GTAGCTTGTCGCTATGCTCT } \\
\text { ATGTC-3' }\end{array}$ & $\begin{array}{l}m c r- \\
2: 193 \text { bp }\end{array}$ \\
\hline & $\begin{array}{l}\text { R:5'CGAGACAGCAGTCAATA } \\
\text { CCGTCAGTTGGCTTGAATGT } \\
\text { CGTA-3' }\end{array}$ & \\
\hline \multirow[t]{2}{*}{$m c r-5$} & $\begin{array}{l}\text { F:5'TAGCACACGCAGAGTAC } \\
\text { GTAGCTTTCATCAGCCTTGT } \\
\text { GTTCA-3' }\end{array}$ & $\begin{array}{l}m c r- \\
5: 140 \mathrm{bp}\end{array}$ \\
\hline & $\begin{array}{l}\text { R:5'CGAGACAGCAGTCAATA } \\
\text { CCGTCATTAGCCATGTTCCA } \\
\text { GAAGT-3' }\end{array}$ & \\
\hline \multirow[t]{2}{*}{$m c r-6$} & $\begin{array}{l}\text { F:5'TAGCACACGCAGAGTAC } \\
\text { GTAGCTCTGTTATCGTATCG } \\
\text { CTATGT-3' }\end{array}$ & $\begin{array}{l}m c r- \\
6: 152 \mathrm{bp}\end{array}$ \\
\hline & $\begin{array}{l}\text { R:5' CGAGACAGCAGTCAATA } \\
\text { CCGTCTCCTTAGACTCGGCT } \\
\text { TGG-3' }\end{array}$ & \\
\hline \multicolumn{3}{|l|}{ Group-B } \\
\hline \multirow[t]{2}{*}{$m c r-3$} & $\begin{array}{l}\text { F: 5'TGCTCATCGTCAGTTCA } \\
\text { C-3, }\end{array}$ & \multirow{2}{*}{$\begin{array}{l}m c r- \\
3: 90 \mathrm{bp}\end{array}$} \\
\hline & $\begin{array}{l}\text { R: 5'ATGGTGTTGTCATAGGT } \\
\text { GTT-3' }\end{array}$ & \\
\hline \multirow[t]{2}{*}{$m c r-4$} & $\begin{array}{l}\text { F: 5'TTAACACCTACGACAAC } \\
\text { ACT-3' }\end{array}$ & \multirow{2}{*}{$\begin{array}{l}m c r- \\
4: 87 \mathrm{bp}\end{array}$} \\
\hline & $\begin{array}{l}\text { R: 5'CGAACATATCCTGCTTA } \\
\text { CCT-3' }\end{array}$ & \\
\hline
\end{tabular}

\subsection{Multiplex PCR for detection of homogeneous mcr variants}

To achieve simultaneous detection of the currently described $m c r$ genes and their variants, we developed several multiplex PCR strategies that involves testing the efficiency of random combinations of primers. Finally, a multiplex PCR strategy consisting of two PCR reactions was screened. Figure 2 presents the melting curves of the six $\mathrm{mcr}$ variants' gene sequences when the homogeneous $m c r$ variant was applied to the newly developed multiplex PCR. Using the DNA of the six bacteria strains positive for $m c r$ variants (Table 1) as the template, products between 87 and 216 bp (Table 2) were amplified with specific primer pairs. The resolution melting curve profiles with distinct $\mathrm{Tm}$ peaks were consistently obtained, and each variant was represented by a single peak ranging from 74.8 to $85.2{ }^{\circ} \mathrm{C}$ (Figure 2). Specifically, in group A, the Tm peak of $m c r-1$ was found at $84.8 \pm 0.02{ }^{\circ} \mathrm{C}$, the $\mathrm{Tm}$ peak of $m c r-2$ was detected at $85.2 \pm 0.01{ }^{\circ} \mathrm{C}$, the Tm peak of $m c r-5$ was observed at $84.1 \pm 0.02{ }^{\circ} \mathrm{C}$ and the Tm peak of $m c r-6$ was found at $83.3 \pm 0.05{ }^{\circ} \mathrm{C}$. In group B, the Tm peak of $m c r$ -
3 was detected at $80.7 \pm 0.02{ }^{\circ} \mathrm{C}$, and the Tm peak of $\mathrm{mcr}$ 4 was observed at $74.8 \pm 0.05^{\circ} \mathrm{C}$ (Figure 2).

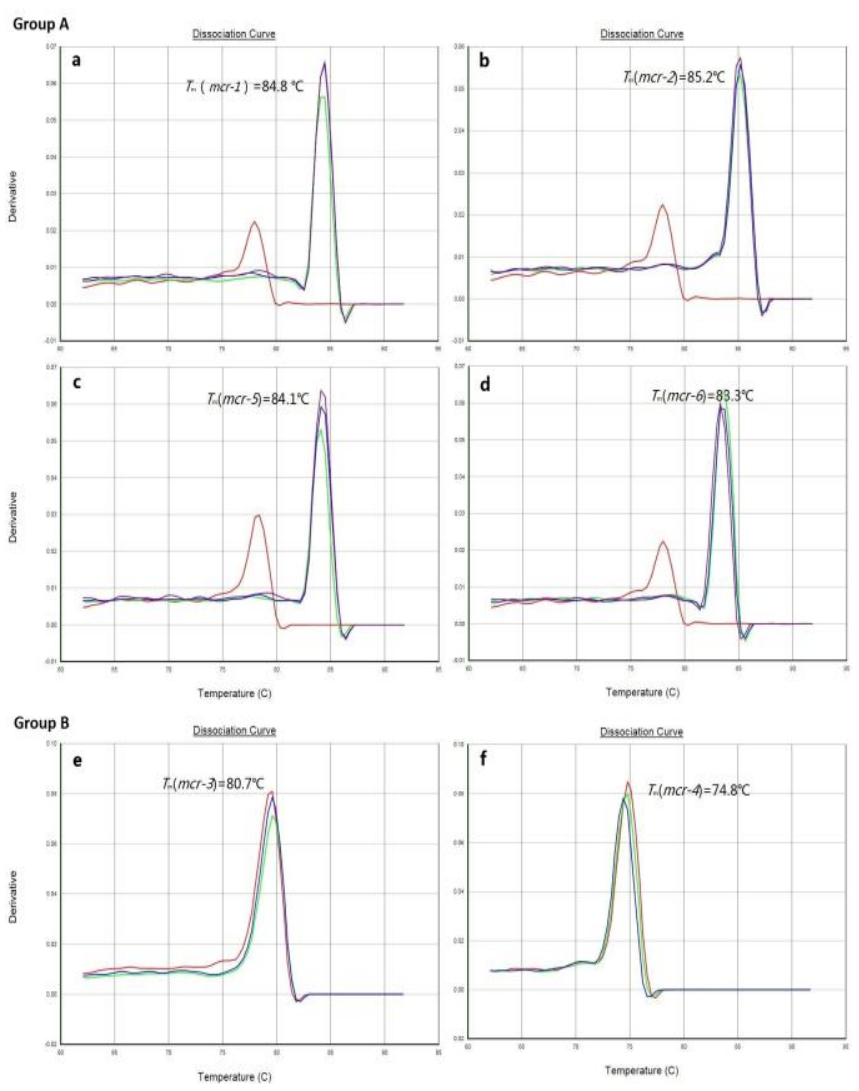

Fig. 2. The melting curves of the six mor genes in the newly developed multiplex PCR.

\subsection{Multiplex PCR for the detection of mixed mcr variants}

Since we have developed a multiplex PCR strategy that could identify $m c r-1$ to $m c r-6$ when they are separately existing. We following try to test its efficiency when several different types of $\mathrm{mcr}$ gene variants co-existing in one sample. According to the results of our pre-tests, primers that target $m c r-1$ and $m c r-3$ react as templates for each other, and the Tm peak of the by-product was $79.9^{\circ} \mathrm{C}$. In reality, $\mathrm{mcr}$ variants scarcely co-exist in a single sample. but to test the efficiency of this multiplex PCR, we mixed six $m c r$ variants proportionally and tested the melting resolution curve profile. When $\mathrm{mcr}-1$ and $m c r-3$ co-existed (Fig. 3a), in group A, the Tm peak of the amplification fragment was found at $84.8 \pm 0.02{ }^{\circ} \mathrm{C}$, which was identical to the result of the single $m c r-1$ test; in group $\mathrm{B}$, the $\mathrm{Tm}$ peak of the amplification fragment was detected at $79.6^{\circ} \mathrm{C} \pm 0.05{ }^{\circ} \mathrm{C}$, which was identical to the by-product. These findings indicate that multiplex PCR could detect only $m c r-1$, rather than both, when $m c r-1$ co-existed with $m c r-3$. When $m c r-2, m c r-5$ and $m c r-6$ co-existed (Fig. 3b), in group A, the Tm peak of the amplification fragment was found at $84.1 \pm 0.02{ }^{\circ} \mathrm{C}$, which was identical to the result of the single $m c r-5$ test; in group B, there was no positive amplification, which indicates that multiplex PCR can only detect $m c r-5$ when $m c r-2, m c r-5$ and $m c r-6$ co-exist. When $m c r-3$ and $m c r-4$ co-existed (Fig. 3c), in group A, the Tm peak of the 
amplification fragment was found at $79.6 \pm 0.05{ }^{\circ} \mathrm{C}$, which was inferred as the by-product; in group $\mathrm{B}$, the Tm peak of the amplification fragment was found both at $74.8 \pm 0.05{ }^{\circ} \mathrm{C}$ and at $80.7 \pm 0.01{ }^{\circ} \mathrm{C}$, which was identical to the findings for singleton $m c r-3$ and $m c r-4$, respectively. This indicates that multiplex PCR can successfully detect $m c r-3$ and $m c r-4$ when they co-exist. In summary, the newly developed multiplex PCR not only detects all MCRs ( $m c r-1$ to $m c r-6)$ effectively when present in the sample as singletons, it can also detect specific MCR genes when they co-exist.

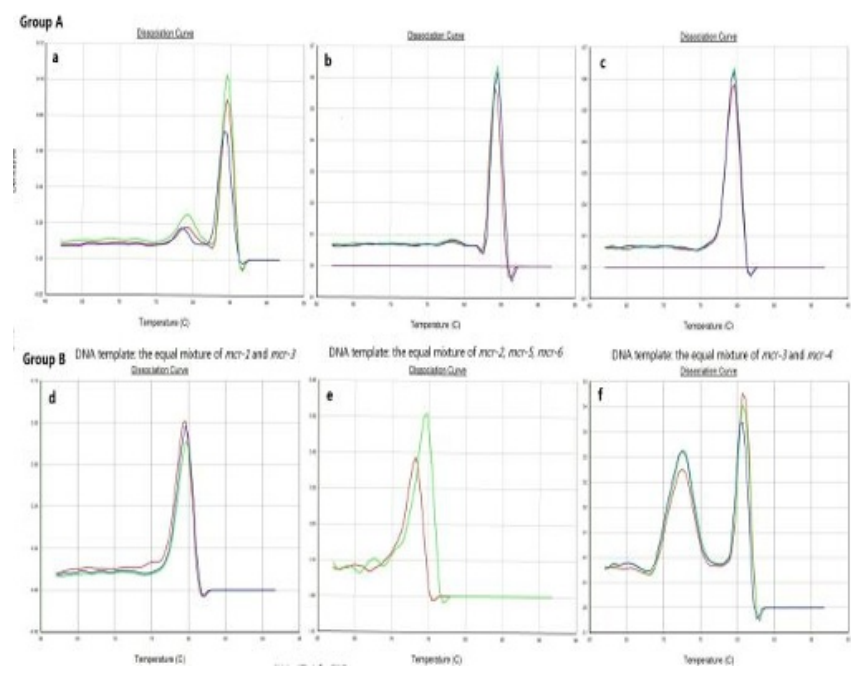

Fig. 3. Multiplex PCR for the detection of mixed $\mathrm{mcr}$ variants

\subsection{Analytical specificity of multiplex PCR assay}

In this study, we assessed the analytical specificity of multiplex PCR analysis with DNA from 33 strains (Table 1) that potentially hosted $\mathrm{mcr}$ variants. After multiplex PCR, positive amplification curves were observed only if the MCR genes (mcr-1 to mcr-6) existed in the culture, and the peaks of the dissolution curves were consistent with those of any standard dissolution curves of $m c r-1$ to $m c r-6$. If the MCR genes did not exist in the culture medium to be examined, no amplification signal was found. These primers have good sensitivity and specificity. Fourteen MCR-positive bacteria strains ( $3 \mathrm{~K}$. pneumoniae and $11 \mathrm{E}$. coli) were correctly identified, whilst no positive fluorescent signal was observed from the 19 non-target controls, which indicates that the method has good specificity.

\subsection{Analytical sensitivity of multiplex PCR assay}

In this study, we determined the analytical sensitivity of the multiplex PCR analysis by analysing various dilutions of purified DNA for each $\mathrm{mcr}$-positive bacteria with 10 -fold diluted genomic DNA from $1 \mathrm{ng}$ to $0.01 \mathrm{pg}$. Figure 4 shows that the detection limit was $1 \mathrm{pg}$ per reaction for $m c r-5$ and $m c r-6,10$ pg per reaction for $m c r-$ 1 and $m c r-2$, and $100 \mathrm{pg}$ per reaction for $m c r-3$ and $m c r-$ 4. As shown in Figure $4 \mathrm{a}$ to $4 \mathrm{~d}$, when the template concentration was lower than the detection limit, the curve shows a peak of the by-product around $79.9{ }^{\circ} \mathrm{C}$, which was identical to that seen in Figure $2 \mathrm{a}$ to $2 \mathrm{~d}$.

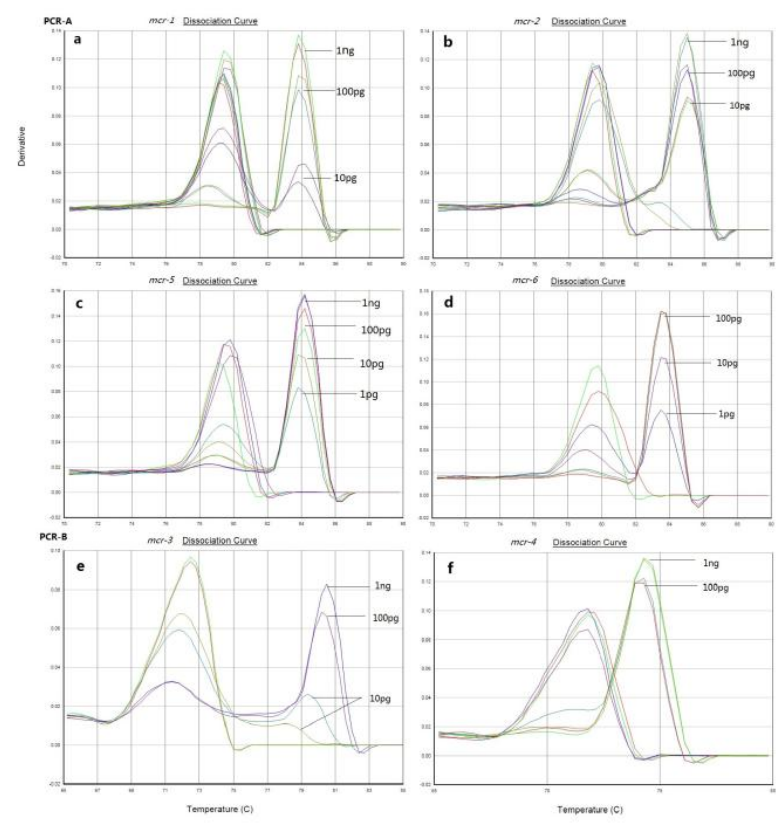

Fig. 4. Analytical sensitivity of the Multiplex PCR assay. The resolution melting curves of 10 -fold diluted genomic DNA of $m c r$-positive E. coli: dilutions $1 \mathrm{ng}$ to $0.01 \mathrm{pg}$, respectively

\subsection{Detection of mcr variants in faecal sample}

One hundred twelve fresh faecal samples were collected from healthy people with the MGI Easy collection suite for intestinal microbial genetic testing; the samples were suspended in buffer solution (v3.0, for research only, MGI) and stored at $4{ }^{\circ} \mathrm{C}$ for less than 1 week. The results show that the positive rate in our study was $13.4 \%$ $(15 / 112)$. While the that positive rate of the same samples was $12.5 \%(14 / 112)$ when there were screened by the method of Shen et al. [17]. This method of extracting DNA from the sample to be measured as a template with good detection rates by boiling method positive MCR genes could be detected both with multiplex PCR and with traditional methods. However, the entire newly developed multiplex PCR procedure can be performed within 1 day.

\section{Discussion}

Plasmid-mediated resistance genes have the potential for further transmission in regions with high levels of antimicrobial resistance and global spread to multidrugresistant bacteria [27]. Colistin has become a last-resort antibiotic for infection of some multi-drug-resistant gram-negative strains [28]. Early detection of MCRpositive bacteria would help setting policy in preventing further spread and providing appropriate antimicrobial therapy. Despite of traditional loop-mediated isothermal amplification, multiplex-LAMP assay has been developed and successfully detection of $m c r-1$ to $m c r-5$ in colistin-resistant bacteria [29,30]. MLST was used to detect and characterise ESBL-producing $E$. coli that express $m c r-1$ obtained from dairy cows in China [18]. In addition to traditional molecular detection, novel methods have also been recently developed, including matrix-assisted laser desorption/ionisation-time of flight mass spectrometry [31], Raman spectroscopy combined 
with hierarchical cluster analysis [32] and liquid chromatography-dual mass spectrometry [33]. Other methods such as the DPA-based BMD test (colistinMAC test) could be implemented by clinical laboratories that were unable to perform molecular tests and was able to screen large collections of isolates to reveal the expression of new $m c r$-like genes that were not targeted by current molecular assays [34], whilst the accuracy of the colistin-MAC test still requires improvement. These methods are limited by their sensitivity and requirement for instruments. For example, the detection sensitivity and specificity of detection methods based on Raman spectroscopy were found to be $90.9 \%$ and $91.1 \%$, respectively, compared with the reference broth microdilution method [32]. In our study, in total of fourteen MCR-positive bacteria strains ( 3 K. pneumoniae and 11 E. coli) were correctly identified, whilst no positive fluorescent signal was observed from the 19 non-target controls. These primers were proofed to have good sensitivity and specificity. Furthermore, the entire newly developed multiplex PCR procedure can be performed within 1 day. In the present study, there solution melting analysis was applied to pure cultures and clinical samples to evaluate its use in detection and species identification of MCR genes in a single real-time PCR assay. The sensitivity and specificity of the $\mathrm{mcr}$ real-time PCR assay were both $100 \%$ in a method validation performed with a set of 112 previously wellcharacterised bacterial isolates that contain $m c r$-positive or $m c r$-negative bacteria. This newly developed assay also led to a significant reduction in the assay volume and reagent costs. This method has potential to be as a low-cost approach of high-through-put screening method for Enterobacteriaceae isolates in which a low prevalence of colistin resistance is expected with minimal hands-on time and costs, and it will assist in combating the spread of colistin resistance in bacteria for its shorter reaction times, simpler instruments and greater sensitivity while showing the same high specificity.

For genotyping of MCR variants, DNA is usually screened firstly with PCR and followed by sequencing of the amplicons $[35,16]$. To distinguish colistin-resistant isolates that carry the plasmid-encoded $\mathrm{mcr}$ genes, many researchers have developed multiplex PCR or other high-throughput detection methods, including in silico tested primers for PCR assay ( $m c r-1$ to $m c r-7)$ [36], multiplex PCR (mcr-1 to mcr-5) [37-39] and multiplex PCR (mcr-1 and $m c r-2)$ [40].While methods discussing the detection efficiency and distinguish ability when two or more types of MCR genes exist in one clinical sample are scarce. The multiplex PCR system developed by Lescat et al. can identify a single isolate with both $m c r-1$ and $m c r-5$ genes [38]. Although $m c r-1$ and $m c r-5$ were not found together, 4 of the 152 samples $(2.7 \%)$ were positive for both $m c r-1$ and $m c r-3$, which indicates that $m c r-1$ and $m c r-3$ did appear at the same time [41]. Our results show that multiplex PCR can successfully detect $m c r-3$ and $m c r-4$ when they co-exist. With the supplement of PCR-A and PCR-B, the kit can successfully detect $m c r-1$ and $m c r-3$ when they co-exist. Furthermore, the PCR-A reaction system of this kit uses a combination of a large number of universal primer pairs and a very small number of specific primers. Specific primers specifically bind to target fragments and amplify them with universal primers using the initial amplified fragments as templates. This combination design can minimise the interaction between primers and improve the efficiency of multiple PCR.

\section{Conclusions}

Colistin is one of the last-resort antibiotics for treatment of multidrug-resistant infections in humans, but transmissible colistin-resistance genes have emerged in bacteria obtained from animals, humans and even food chain. The rapid and sensitive detection bacteria that carry these genes in clinical samples is critical to help control further spread. Here we describe a method for broth enrichment of colistin-resistant $E$. coli from human faecal samples followed by multiplex-PCR for simultaneous detection of two of the main colistinresistance genes, $m c r-1$ to $m c r-6$.Real-time monitoring of the PCR products will greatly reduce the monitoring mobility of colistin tolerance. The purpose of the newly developed multiplex PCR is to provide a method to detect the MCR gene, which according to the existing technology rarely covers all MCR genes (ranging from $m c r-1$ to $m c r-6$ ). Based on all MCR gene sequences found to date, we designed two multiplex PCR systems for detection of all MCRs. This method is especially suitable for medical, clinical or environmental monitoring scenarios. It can detect any MCR genes in faecal samples quickly, simply and effectively. The realtime monitoring of PCR products will greatly reduce the resource consumption in our daily monitoring task. Furthermore, the group A system consists of a large portion of universal primer pairs and a very small portion of specific primers. These specific primers specifically bind to target fragments and amplify them by universal primers using the initial amplified fragments as templates. This combination strategy can minimise the interaction between primers and improve the efficiency of multiple PCR. The method adopts PCR technology as the fluorescence detection method, and the reaction was carried out in a closed-tube reactor to prevent PCR electrophoresis from forming aerosol pollution caused by false-positive results.

\section{Acknowledgments}

This work was supported by funds including the Postdoctoral Research Foundation of China (No. 2018M643202), National Key Research and Development Program of China (No.2019YFC1605104), Sanming Project of Medicine in Shenzhen (SZSM201611068) and Science and Technology Planning Project of Shenzhen Municipality (JCYJ20170413 101841798 and JCYJ20190807103003724).

\section{References}

[1] M. AbuOun, E. J. Stubberfield, N. A. Duggett, M. Kirchner, L. Dormer, J. Nunez-Garcia, L. P. Randall, F. Lemma, D. W. Crook, C. Teale, R. P. Smith, and M. F. Anjum, 'Mcr-1 and Mcr-2 Variant 
Genes Identified in Moraxella Species Isolated from Pigs in Great Britain from 2014 to 2015', J Antimicrob Chemother, 72 (2017), 2745-49.

[2] M Borowiak, J Fischer, J. A. Hammerl, R. S. Hendriksen, I Szabo, and B Malorny, 'Identification of a Novel Transposon-Associated Phosphoethanolamine Transferase Gene, Mcr-5, Conferring Colistin Resistance in D-Tartrate Fermenting Salmonella Enterica Subsp. Enterica Serovar Paratyphi B', J Antimicrob Chemother, 72 (2017), 3317.

[3] T. Budel, M. Clement, O. J. Bernasconi, L. Principe, V. Perreten, F. Luzzaro, and A. Endimiani, 'Evaluation of Edta- and Dpa-Based Microdilution Phenotypic Tests for the Detection of McrMediated Colistin Resistance in Enterobacteriaceae', Microbial Drug Resistance, 7.

[4] Wang C, Feng Y, Liu L, Wei L, Kang M, and Zong Z, 'Mcr-10identification of Novel Mobile Colistin Resistance Gene', Emerging microbes \& infections, 9 (2020), 508-16.

[5] A. Carattoli, L. Villa, C. Feudi, L. Curcio, S. Orsini, A. Luppi, G. Pezzotti, and C. F. Magistrali, 'Novel Plasmid-Mediated Colistin Resistance Mcr-4 Gene in Salmonella and Escherichia Coli, Italy 2013, Spain and Belgium, 2015 to 2016', Eurosurveillance, 22 (2017).

[6] Boudewijn Catry, Marco Cavaleri, Keith Baptiste, Kari Grave, Kornelia Grein, Anja Holm, Helen Jukes, Ernesto Liebana, Antonio Lopez Navas, and David Mackay, 'Use of Colistin-Containing Products within the European Union and European Economic Area (Eu/Eea): Development of Resistance in Animals and Possible Impact on Human and Animal Health', International Journal of Antimicrobial Agents, 46 (2015), 297-306.

[7] J. B. Daniels, D. Campbell, S. Boyd, U. Ansari, J. Lutgring, J. K. Rasheed, A. L. Halpin, and M. Sjolund-Karlsson, 'Development and Validation of a Clinical Laboratory Improvement AmendmentsCompliant Multiplex Real-Time Pcr Assay for Detection of Mcr Genes', Microbial Drug Resistance, 6.

[8] L. Dortet, R. A. Bonnin, I. Pennisi, L. Gauthier, A. B. Jousset, L. Dabos, R. C. D. Furniss, D. A. I. Mavridou, P. Bogaerts, Y. Glupczynski, A. Potron, P. Plesiat, R. Beyrouthy, F. Robin, R. Bonnet, T. Naas, A. Filloux, and G. Larrouy-Maumus, 'Rapid Detection and Discrimination of Chromosome-and Mcr-Plasmid-Mediated Resistance to Polymyxins by Maldi-Tof Ms in Escherichia Coli: The Maldixin Test', Journal of Antimicrobial Chemotherapy, 73 (2018), 3359-67.

[9] Y Feng., 'New Multiplex Pcr Primer Comprising Five Primer Pairs Having Specified Base Pair Sequences, Useful for Detecting Polymyxin Resistance Genes, Preferably Mobilized Colistin Resistance Genes, and Distinguishing Corresponding Resistance Genes', (QINGDAO ZHIYE BIOTECHNOLOGY CO LTD (QINGNon-standard), 2018), p. 10.
[10] Magistrali Chiara Francesca, Curcio Ludovica, Luppi Andrea, Pezzotti Giovanni, Orsini Serenella, Tofani Silvia, Feudi Claudia, Carattoli Alessandra, and Villa Laura, 'Mobile Colistin Resistance Genes in Escherichia Coli from Pigs Affected by Colibacillosis', International Journal of Antimicrobial Agents (2019).

[11] C Garciagraells, De Keersmaecker Scj, K Vanneste, B Pochet, K Vermeersch, N Roosens, K Dierick, and $\mathrm{N}$ Botteldoorn, 'Detection of Plasmid-Mediated Colistin Resistance, Mcr-1 and Mcr-2 Genes, in Salmonella Spp. Isolated from Food at Retail in Belgium from 2012 to 2015', Foodborne Pathogens \& Disease, 15 (2017).

[12] Tao He, Ran Wang, Dejun Liu, Timothy R. Walsh, Rong Zhang, Yuan Lv, Yuebin Ke, Quanjiang Ji, Ruicheng Wei, Zhihai Liu, Yingbo Shen, Gang Wang, Lichang Sun, Lei Lei, Ziquan Lv, Yun Li, Maoda Pang, Liyuan Wang, Qiaoling Sun, Yulin $\mathrm{Fu}$, Huangwei Song, Yuxin Hao, Zhangqi Shen, Shaolin Wang, Gongxiang Chen, Congming Wu, Jianzhong Shen, and Yang Wang, 'Emergence of Plasmid-Mediated High-Level Tigecycline Resistance Genes in Animals and Humans', Nature Microbiology, 4 (2019), 1450-56.

[13] Shuangfang $\mathrm{Hu}$, Yigang Yu, Xinwei Wu, Xingzhou $\mathrm{Xia}$, and $\mathrm{Wu}$ Hui, 'Simultaneous Detection and Identification of Pathogenic Cronobacter Species by High-Resolution Melting Analysis in Powdered Infant Formulas', International Journal of Dairy Technology, 71 (2017).

[14] C Imirzalioglu, L Falgenhauer, J Schmiedel, S. E. Waezsada, K Gwozdzinski, N Roschanski, U Roesler, L Kreienbrock, A. P. Schiffmann, and A Irrgang, 'Evaluation of a Loop-Mediated Isothermal Amplification-Based Assay for the Rapid Detection of Plasmid-Encoded Colistin Resistance Gene Mcr1 in Enterobacteriaceae Isolates', Antimicrob Agents Chemother, 61 (2017), AAC.02326-16.

[15] A. B. Jousset, S. Bernabeu, R. A. Bonnin, E. Creton, G. Cotellon, A. Sauvadet, T. Naas, and L. Dortet, 'Development and Validation of a Multiplex Polymerase Chain Reaction Assay for Detection of the Five Families of Plasmid-Encoded Colistin Resistance', International Journal of Antimicrobial Agents, 53 (2019), 302-09.

[16] N Kieffer, G Royer, JW Decousser, AS Bourrel, M Palmieri, De La Rosa JM Ortiz, H Jacquier, E Denamur, P Nordmann, and L Poirel, 'Mcr-9, an Inducible Gene Encoding an Acquired Phosphoethanolamine Transferase in Escherichia Coli, and Its Origin', Antimicrobial agents and chemotherapy, 63 (2019).

[17] M. Lescat, L. Poirel, and P. Nordmann, 'Rapid Multiplex Polymerase Chain Reaction for Detection of Mcr-1 to Mcr-5 Genes', Diagnostic Microbiology And Infectious Disease, 92 (2018), 267-69.

[18] J. Li, J. Cao, Y. G. Zhu, Q. L. Chen, F. Shen, Y. Wu, S. Xu, H. Fan, G. Da, and R. J. Huang, 'Global Survey of Antibiotic Resistance Genes in Air', 
Environmental Science \& Technology, 52 (2018), acs.est.8b02204-

[19] Zhongquan Lin, Xiang Zhao, Jiaoqi Huang, Wei Liu, Yuting Zheng, Xiang Yang, Yang Zhang, Marc Lamy de la Chapelle, and Weiling Fu, 'Rapid Screening of Colistin-Resistant Escherichia Coli, Acinetobacter Baumannii and Pseudomonas Aeruginosa by the Use of Raman Spectroscopy and Hierarchical Cluster Analysis', Analyst, 144 (2019), $2803-10$

[20] Yi Yun Liu, Yang Wang, Timothy R Walsh, Ling Xian Yi, Rong Zhang, James Spencer, Yohei Doi, Guobao Tian, Baolei Dong, and Xianhui Huang, 'Emergence of Plasmid-Mediated Colistin Resistance Mechanism Mcr-1 in Animals and Human Beings in China: A Microbiological and Molecular Biological Study', Lancet Infectious Diseases, 16 (2016), 161-68.

[21] Nenad Macesic, Sabrina Kahn, Marla J. Giddins, Daniel Freedberg, Susan Whittier, Daniel Green, E. Yoko Furuya, Elizabeth C. Verna, Medini K. Annavajhala, Angela Gomez-Simmonds, and Anne-Catrin Uhlemann, 'Escherichia Coli Harboring Mcr-1 in a Cluster of Liver Transplant Recipients: Detection through Active Surveillance and Whole Genome Sequencing', Antimicrobial Agents and Chemotherapy (2019), AAC.02680-18.

[22] P. Mlynarcik, and M. Kolar, 'Molecular Mechanisms of Polymyxin Resistance and Detection of Mcr Genes', Biomedical PapersOlomouc, 163 (2019), 28-38.

[23] NIH,

'Https://Www.Ncbi.Nlm.Nih.Gov/Pathogens/Isolate s\#/Refgene/Gene Family:(Mcr-1)', (2019).

[24] M Rhouma, F Beaudry, W Thériault, and A Letellier, 'Colistin in Pig Production: Chemistry, Mechanism of Antibacterial Action, Microbial Resistance Emergence, and One Health Perspectives', Frontiers in Microbiology, 7 (2016), 1789.

[25] Kade D. Roberts, Mohammad A. K. Azad, Jiping Wang, Andrew S. Horne, Philip E. Thompson, Roger L. Nation, Tony Velkov, and Jian Li, 'Antimicrobial Activity and Toxicity of the Major Lipopeptide Components of Polymyxin B and Colistin: Last-Line Antibiotics against MultidrugResistant Gram-Negative Bacteria', ACS Infectious Diseases, 1 (2015), 568-75.

[26] Yingbo Shen, Hongwei Zhou, Xu Jiao, Yongqiang Wang, Qijing Zhang, Timothy R. Walsh, Shao Bing, Congming $\mathrm{Wu}$, Yanyan $\mathrm{Hu}$, and Yang $\mathrm{Lu}$, 'Anthropogenic and Environmental Factors Associated with High Incidence of Mcr-1 Carriage in Humans across China', Nature Microbiology, 3 (2018), 1.

[27] Yingbo Shen, Hongwei Zhou, Jiao Xu, Yongqiang Wang, Qijing Zhang, Timothy R. Walsh, Bing Shao, Congming $\mathrm{Wu}$, Yanyan $\mathrm{Hu}$, Lu Yang, Zhangqi Shen, Zuowei $\mathrm{Wu}$, Qiaoling Sun, Yanran Ou, Yueling Wang, Shaolin Wang, Yongning Wu, Chang Cai, Juan Li, Jianzhong Shen, Rong Zhang, and Yang Wang, 'Anthropogenic and Environmental Factors Associated with High Incidence of Mcr-1 Carriage in Humans across China', Nature Microbiology, 3 (2018), 1054-62.

[28] Jian Sun, Huimin Zhang, Ya Hong Liu, and Youjun Feng, 'Towards Understanding Mcr-Like Colistin Resistance', Trends in Microbiology (2018).

[29] Q. L. Sun, Y. Y. Hu, H. W. Zhou, L. B. Shu, H. Y. Wang, Z. X. Huang, and R. Zhang, 'Alkaline Peptone Water-Based Enrichment Method for Mcr3 from Acute Diarrheic Outpatient Gut Samples', Frontiers In Medicine, 5 (2018), 6.

[30] Damien Thiry, Anis Berrah, Julien Evrard, JeanNoël Duprez, Jacques G. Mainil, and Marc Saulmont, 'Assessment of Two Selective Agar Media to Isolate Colistin-Resistant Bovine Escherichia Coli: Correlation with Minimal Inhibitory Concentration and Presence of Mcr Genes', Journal of Microbiological Methods, 159 (2019), 174-78.

[31] H. H. Wang, Y. Chen, J. R. Strich, S. K. Drake, J. H. Youn, A. Z. Rosenberg, M. Gucek, P. T. McGann, A. F. Suffredini, and J. P. Dekker, 'Rapid Detection of Colistin Resistance Protein Mcr-1 by Lc-Ms/Ms', Clinical Proteomics, 16 (2019), 10.

[32] Xiaoming Wang, Yao Wang, Ying Zhou, Jiyun Li, Wenjuan Yin, Shaolin Wang, Suxia Zhang, Jianzhong Shen, Zhangqi Shen, and Yang Wang, 'Emergence of a Novel Mobile Colistin Resistance Gene, Mcr-8 , in Ndm-Producing Klebsiella Pneumoniae', Emerging Microbes \& Infections, 7 (2018), 122-.

[33] Y Wang, F Liu, Y Hu, G Zhang, B Zhu, and GF Gao, 'Detection of Mobile Colistin Resistance Gene Mcr-9 in Carbapenem-Resistant Klebsiella Pneumoniae Strains of Human Origin in Europe', The Journal of infection (2019).

[34] Y. Wang, G. B. Tian, R. Zhang, Y. Shen, J. M. Tyrrell, X. Huang, H. Zhou, L. Lei, H. Y. Li, Y. Doi, Y. Fang, H. Ren, L. L. Zhong, Z. Shen, K. J. Zeng, S. Wang, J. H. Liu, C. Wu, T. R. Walsh, and J. Shen, 'Prevalence, Risk Factors, Outcomes, and Molecular Epidemiology of Mcr-1-Positive Enterobacteriaceae in Patients and Healthy Adults from China: An Epidemiological and Clinical Study', Lancet Infect Dis, 17 (2017), 390-99.

[35] Z. Wang, Y. Fu, S. Schwarz, W. Yin, T. R. Walsh, Y. Zhou, J. He, H. Jiang, Y. Wang, and S. Wang, 'Genetic Environment of Colistin Resistance Genes Mcr-1 and Mcr-3 in Escherichia Coli from One Pig Farm in China', Vet Microbiol, 230 (2019), 56-61.

[36] B. B. Xavier, C Lammens, R Ruhal, S KumarSingh, P Butaye, H Goossens, and S MalhotraKumar, 'Identification of a Novel PlasmidMediated Colistin-Resistance Gene, Mcr-2, in Escherichia Coli, Belgium, June 2016', (2016).

[37] Y. Q. Yang, Y. X. Li, C. W. Lei, A. Y. Zhang, and H. N. Wang, 'Novel Plasmid-Mediated Colistin Resistance Gene Mcr-7.1 in Klebsiella Pneumoniae', Journal of Antimicrobial Chemotherapy, 73 (2018). 
[38] W. Yin, H. Li, Y. Shen, Z. Liu, S. Wang, Z. Shen, R. Zhang, T. R. Walsh, J. Shen, and Y. Wang, 'Novel Plasmid-Mediated Colistin Resistance Gene Mcr-3 in Escherichia Coli', MBio, 8 (2017).

[39] J. Zhang, L. Chen, J. Wang, A. K. Yassin, P Butaye, P Kelly, J. Gong, W. Guo, J. Li, and M. Li, 'Molecular Detection of Colistin Resistance Genes (Mcr-1, Mcr-2 and Mcr-3) in Nasal/Oropharyngeal and Anal/Cloacal Swabs from Pigs and Poultry', Sci Rep, 8 (2018), 3705.

[40] B. W. Zheng, C. Y. Feng, H. Xu, X. Yu, L. H. Guo, $\mathrm{X}$. W. Jiang, and X. H. Song, 'Detection and Characterization of Esbl-Producing Escherichia Coli Expressing Mcr-1 from Dairy Cows in China', Journal of Antimicrobial Chemotherapy, 74 (2019), 321-25.

[41] Zhou Q Zhong LL, Tan CY, Roberts AP, El-Sayed Ahmed MAEG, Chen G, Dai M, Yang F, Xia Y, Liao K, Liang Y, Yang Y, Feng S, Zheng X, Tian GB, 'Multiplex Loop-Mediated Isothermal Amplification (Multi-Lamp) Assay for Rapid Detection of Mcr-1 to Mcr-5 in Colistin-Resistant Bacteria', Infection and Drug Resistance 12 (2019), 1877-87. 